\title{
CrystEngComm
}

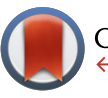

CrossMark <click for updates

Cite this: CrystEngComm, 2016, 18 3237

Received 27th February 2016, Accepted 4th April 2016

DOI: $10.1039 / c 6 c e 00464 d$

www.rsc.org/crystengcomm

\section{Thermal strain-induced cold crystallization of amorphous poly(lactic acid) $\dagger$}

\author{
Chengbo Zhou, ${ }^{\text {ab }}$ Hongfei Li, ${ }^{\text {aa }}$ Wenyang Zhang, ${ }^{\text {ab }}$ Jingqing Li, ${ }^{b}$ Shaoyong Huang, ${ }^{c}$ \\ Yanfeng Meng, ${ }^{d}$ Jesper de Claville Christiansen, ${ }^{d e}$ Donghong $\mathrm{Yu}^{\mathrm{f}}{ }^{\mathrm{Z}} \mathrm{Zhonghua} \mathrm{Wu}^{\mathrm{g}}$ \\ and Shichun Jiang*ab
}

\begin{abstract}
The cold crystallization behaviors and structure evolutions of amorphous PLA stretched within a hightemperature range $\left(100-150^{\circ} \mathrm{C}\right)$ were investigated via in situ synchrotron WAXS and SAXS measurements. The PLA stretched at $120{ }^{\circ} \mathrm{C}$ exhibits excellent mechanical properties with the highest modulus, stretching strength and moderate elongation, which is attributed to the coordination effect of thermally-induced initial crystallinity and moderate chain segment mobility. The WAXS results showed that the diffraction peaks of $(200 / 110)$ and (203) planes shift to higher $2 \theta$ values, which indicates the formation of more ordered $\alpha^{\prime}$ and $\alpha$ forms during PLA stretching within 100-150 ${ }^{\circ} \mathrm{C}$. More $\alpha$ forms can be formed from the stretched $\alpha^{\prime}$ form and/or from the amorphous phase at $100^{\circ} \mathrm{C}$. The phase diagram of $\alpha$ and $\alpha^{\prime}$ forms in stretched PLA with stretching temperature was proposed according to the obtained data of lattice spacing. The crystallinity of stretched PLA increases faster than that which underwent quiescent cold crystallization at the same temperature. The SAXS results indicated that the long period and lamellar thickness along and vertical to the stretching direction of PLA stretched within $100-150{ }^{\circ} \mathrm{C}$ exhibit distinct variations, which is attributed to the difference of strain-induced crystallization and lamellar orientation.
\end{abstract}

\section{Introduction}

Biosourced polymers have attracted increasing attention in recent years due to their potential to replace petroleum-based commodity polymers. ${ }^{1}$ Among such polymers, poly(lactic acid) (PLA) is one of the most promising bio-based polymers for use as bio-implants, surgical structural materials, drug delivery systems and biodegradable packaging due to its high strength, high modulus, good clarity as well as good biode-

\footnotetext{
${ }^{a}$ State Key Laboratory of Polymer Physics and Chemistry, Changchun Institute of Applied Chemistry, Chinese Academy of Sciences, Changchun 130022, PR China. E-mail: hfli@ciac.ac.cn,scjiang@tju.edu.cn

${ }^{b}$ School of Materials Science and Engineering, Tianjin University, Tianjin 300072, PR China

${ }^{c}$ Key Laboratory of Polymer Eco-materials, Changchun Institute of Applied Chemistry, Chinese Academy of Sciences, Changchun 130022, PR China

${ }^{d}$ School of Chemistry and Materials Science, Ludong University, Yantai 264025, PR China

${ }^{e}$ Department of Mechanical and Manufacturing Engineering, Aalborg University, DK-9220, Aalborg, Denmark

${ }^{f}$ Department of Chemistry and Biosciences, Aalborg University, DK-9220, Aalborg, Denmark

${ }^{g}$ Beijing Synchrotron Radiation Laboratory, Institute of High Energy Physics,

Chinese Academy of Sciences, Beijing 100039, PR China

$\dagger$ Electronic supplementary information (ESI) available. See DOI: 10.1039/ c6ce00464d
}

gradability and biocompatibility. ${ }^{2-6}$ The properties of PLA products, such as the thermal resistance, degradation rate as well as optical, mechanical and barrier properties, are related to the crystalline phase of PLA, ${ }^{6,7}$ therefore it is important to control the crystalline structures and crystallization kinetics of PLA during processing.

The $\alpha$ and $\alpha^{\prime}$ forms of PLA have been identified according to wide-angle X-ray diffraction (WAXD) and infrared spectroscopy (IR) measurements. The $\alpha$ form of a pseudo-orthorhombic structure with each unit cell containing two $10_{3}$ helical chains was identified by De Santis and Kovacs, ${ }^{8}$ which can be obtained by isothermal crystallization above $120{ }^{\circ} \mathrm{C}$ (ref. 9 and 10) or by stretching a solution-spun PLLA fiber at relatively low drawing temperatures and/or low hot-draw ratios. ${ }^{11}$ The $\alpha^{\prime}$ form (or $\delta$ form), similar to the $\alpha$ form but with loose chain packing and disordered $10_{3}$ helical conformations, was proposed by Zhang et al. ${ }^{12}$ for PLA crystallized below $120{ }^{\circ} \mathrm{C}$. Due to its metastability ${ }^{13}$ the $\alpha^{\prime}$ form can transform into the $\alpha$ form with increasing temperature up to around $160{ }^{\circ} \mathrm{C}$ just before its melting point ${ }^{9,14}$ through the transition mechanism of the ordering of chain conformation along with the regularization of chain packing as well as the relative height matching of the neighboring $\alpha^{\prime}$ domain. ${ }^{15}$ The $\alpha$ form of the PLA crystal can be obtained at lower temperatures (below $100{ }^{\circ} \mathrm{C}$ ) with strong shearing. ${ }^{3}$ The properties of PLA are related to the content ratio of the $\alpha$ and $\alpha^{\prime}$ forms. The higher 
content of the $\alpha$ form will enhance Young's modulus and the barrier to water vapor of PLA films. ${ }^{16}$

Stretching amorphous PLA samples at different temperatures and drawing rates can induce different ordered structures. When the stretching temperatures did not exceed $70{ }^{\circ} \mathrm{C}$, the amorphous PLA-containing mesophase ${ }^{17}$ was stretched into the less ordered mesocrystal due to the relatively low chain segment mobility. ${ }^{1,18-26}$ When the drawing temperature was higher than $70^{\circ} \mathrm{C}$, the amorphous PLA could be drawn into both the mesocrystal and crystal at lower temperatures and into the crystal only at higher temperatures. ${ }^{1,4,19,20,27}$ Above $100{ }^{\circ} \mathrm{C}$, the degrees of strain-induced crystallization and crystal orientation decrease pronouncedly due to the high chain relaxation. ${ }^{25}$ With the drawing rate increasing, the upper temperature limitation of the strain-induced mesocrystal formation shifts to a higher value, due to the beneficial effect of higher chain orientation induced by the higher drawing rate on the formation of the strain-induced mesocrystal. ${ }^{1,19}$ The strain-induced crystallinity and degree of crystal orientation as well as cavitations increase with strain rate, leading to stronger strain-hardening. ${ }^{4}$

The strain-induced ordered structures (mesocrystal and crystal) and crystal orientation of amorphous PLA stretched at a wide temperature range have been investigated extensively. However, the strain-induced variations of crystalline structures (containing lamellae and forms of the crystal) during stretching at different temperatures have been rarely reported. In the present work, the effects of strain on the variation of crystal structures ( $\alpha$ and $\alpha^{\prime}$ forms) and cold crystallization behavior together with the mechanical properties of stretched PLA were investigated within 100-150 ${ }^{\circ} \mathrm{C}$. Based on the in situ synchrotron WAXS/SAXS results, the straininduced variation of the stacked lamellar structure of PLA during stretching within $100-150{ }^{\circ} \mathrm{C}$ was discussed.

\section{Experimental section}

\subsection{Material and sample preparation}

Material. Poly(lactic acid) (PLA) (containing $0.8 \mathrm{wt} \%$ D-isomer unit) was provided by Zhejiang Hisun Biomaterials Co., Ltd. (China), with the number average molecular weight $\left(M_{\mathrm{n}}\right)$ of $88.2 \times 10^{3} \mathrm{~g} \mathrm{~mol}^{-1}$ and polydispersity index (PDI) of 1.24. The glass transition temperature $\left(T_{\mathrm{g}}\right)$, cold crystallization temperature $\left(T_{\mathrm{cc}}\right)$ and melting point $\left(T_{\mathrm{m}}\right)$ determined by DSC (DSC-Q20, from TA Co.) measurement were $63.5{ }^{\circ} \mathrm{C}$, $102.3^{\circ} \mathrm{C}$ and $176.4^{\circ} \mathrm{C}$, respectively.

Sample preparation. PLA granules were dried in a vacuum oven at $50{ }^{\circ} \mathrm{C}$ for 24 hours, and then melted at $200{ }^{\circ} \mathrm{C}$ and compressed into a sheet with a thickness of about $0.5 \mathrm{~mm}$. After long enough time under $20 \mathrm{MPa}$, the melted PLA sheet was immersed in ice water as soon as possible to obtain amorphous PLA samples. Dumbbell-shaped amorphous sample bars with dimensions of $26.0 \mathrm{~mm}$ (gauge length) $\times 3.0$ $\mathrm{mm}$ (neck length) $\times 2.1 \mathrm{~mm}$ (neck width) were cut from the amorphous PLA sheet for in situ structure determination dur- ing stretching. At the same time, annealed PLA samples were prepared by annealing amorphous PLA at $70^{\circ} \mathrm{C}, 80^{\circ} \mathrm{C}, 90^{\circ} \mathrm{C}$, $100{ }^{\circ} \mathrm{C}, 120^{\circ} \mathrm{C}$ and $150^{\circ} \mathrm{C}$ in a vacuum oven for 12 hours. In the present study, the amorphous PLA sample is labeled as aPLA, and the PLA samples annealed at $70{ }^{\circ} \mathrm{C}, 80^{\circ} \mathrm{C}, 90{ }^{\circ} \mathrm{C}$, $100{ }^{\circ} \mathrm{C}, 120{ }^{\circ} \mathrm{C}$ and $150{ }^{\circ} \mathrm{C}$ for 12 hours are labeled as A70PLA, A80PLA, A90PLA, A100PLA, A120PLA and A150PLA, respectively. The meanings of "a" and "A $i$ " in the above sample names are "amorphous" and "annealed at $i{ }^{\circ} \mathrm{C}$ ", respectively.

\subsection{Tensile measurements}

The amorphous PLA bars were heated to $100{ }^{\circ} \mathrm{C}, 120^{\circ} \mathrm{C}$ and $150{ }^{\circ} \mathrm{C}$ with a temperature equilibrium time of 1 minute, and then stretched at a drawing rate of $1 \mu \mathrm{m} \mathrm{s} \mathrm{s}^{-1}$ by using a Linkam TST350 hot tensile stage (Linkam Scientific Instruments, Ltd., U.K.), which could draw the bar symmetrically so that the incident beam could illuminate the same position of the sample. For comparison of the mechanical properties of the different PLA samples under different temperatures, the amorphous PLA was stretched at $70{ }^{\circ} \mathrm{C}, 80^{\circ} \mathrm{C}$ and $90{ }^{\circ} \mathrm{C}$, and the A70PLA, A80PLA, A90PLA, A100PLA, A120PLA and A150PLA samples were stretched at the corresponding annealing temperatures. The stress and strain mentioned in this study are all engineering stress and engineering strain obtained from the tensile hot stage.

\subsection{In situ synchrotron SAXS and WAXS measurements}

In situ synchrotron SAXS and WAXS measurements of the amorphous PLA samples during stretching at $100{ }^{\circ} \mathrm{C}, 120^{\circ} \mathrm{C}$ and $150{ }^{\circ} \mathrm{C}$ with a drawing rate of $1 \mu \mathrm{m} \mathrm{s}^{-1}$ were performed at beamline $1 \mathrm{~W} 2 \mathrm{~A}(\lambda=0.154 \mathrm{~nm})$ of the Beijing Synchrotron Radiation Facility (BSRF, Beijing, China) ${ }^{28}$ with a Mar165CCD detector (MAR USA, with a resolution of $2048 \times 2048$ pixels and a pixel size of $79 \times 79 \mu \mathrm{m}^{2}$ ). The sample-detector distances of $1550 \mathrm{~mm}$ and $90 \mathrm{~mm}$ were adopted for the SAXS and WAXS measurements, respectively. The corresponding background of the air and tensile device between the sample and the detector was recorded and subtracted from all of the $2 \mathrm{D}$ patterns. ${ }^{29}$

\section{Results and discussion}

\subsection{Mechanical properties under different stretching temperatures}

The engineering stress-strain curves of the amorphous PLA samples stretched uniaxially within $100-150{ }^{\circ} \mathrm{C}$ are shown in Fig. 1a. The mechanical properties of amorphous PLA showed an abnormal change with drawing temperature within $100-150{ }^{\circ} \mathrm{C}$. In the elastic deformation region (strain lower than 2\%), the Young's modulus of PLA stretched at 100 ${ }^{\circ} \mathrm{C}$ is the lowest, that at $120{ }^{\circ} \mathrm{C}$ is the highest, and that at 150 ${ }^{\circ} \mathrm{C}$ is located between them. After the elastic deformation stage, the stress of PLA drawn at $100{ }^{\circ} \mathrm{C}$ increases linearly 
and exceeds that at $150{ }^{\circ} \mathrm{C}$ with strain larger than $3 \%$. However, neither the stress of PLA drawn at $100{ }^{\circ} \mathrm{C}$ nor that at $150{ }^{\circ} \mathrm{C}$ can exceed that at $120{ }^{\circ} \mathrm{C}$. In all of the stretching processes, the amorphous PLA drawn at $120{ }^{\circ} \mathrm{C}$ has the highest modulus, stretching strength and moderate elongation, showing the best mechanical properties.

To understand the mechanical behaviors shown in Fig. 1a, the Young's modulus of amorphous PLA and annealed PLA stretched within a wider temperature range and the difference between them varying with drawing temperature are shown in Fig. 1b and c, respectively. As shown in Fig. 1b, the Young's modulus of annealed PLA with annealing-induced constant crystallinity decreases with increasing drawing temperature due to the activation of vibration and movement of polymer chain segments induced by high drawing temperatures. $^{30}$ The Young's modulus of amorphous PLA also decreases with drawing temperature within 70-100 ${ }^{\circ} \mathrm{C}$; however, it shows a fluctuating change within $100-150{ }^{\circ} \mathrm{C}$. Correspondingly, the discrepancy of Young's modulus between annealed and amorphous PLA $(\Delta E)$ stretched within 100-150 ${ }^{\circ} \mathrm{C}$ also shows an anomalous variation compared to that within 70$100{ }^{\circ} \mathrm{C} . \Delta E$ remains almost constant within the drawing temperature of $70-80{ }^{\circ} \mathrm{C}$. At moderate drawing temperatures, i.e. 80-100 ${ }^{\circ} \mathrm{C}, \Delta E$ begins to decrease and gradually falls to zero when the drawing temperature is higher than $100{ }^{\circ} \mathrm{C}$. The anomalous variation of Young's modulus of amorphous PLA stretched within $100-150{ }^{\circ} \mathrm{C}$ will be discussed in detail in the next section.

\subsection{In situ WAXS/SAXS measurements}

To identify the mechanical behavior-related structures of amorphous PLA stretched within $100-150{ }^{\circ} \mathrm{C}$, in situ synchrotron SAXS and WAXS measurements were performed to investigate the structure evolutions of PLA during the drawing process. Selective 2D SAXS and WAXS patterns acquired in the stretching process together with the stress-strain curves are shown in Fig. 2. As shown in Fig. 2a, the WAXS pattern of the undrawn PLA sample shows two weak scattering rings, corresponding to the $(200 / 110)$ and (203) planes, respectively, from inner to outer. Meanwhile, the SAXS pattern of the undrawn sample exhibits no scattering halo of the stacked lamellar structure. This reveals that the thermally-induced initial crystallinity of PLA at $100{ }^{\circ} \mathrm{C}$ is low. The scattering rings of (200/ 110) and (203) planes in the WAXS patterns become stronger with strain. Meanwhile, the scattering halo of the stacked lamellae $^{31}$ in the SAXS patterns appears gradually and becomes stronger along the equator, as shown in the SAXS patterns from $3 \mathrm{~S}$ to $6 \mathrm{~S}$. This indicates that the crystallinity increases and the crystalline layer forms and orients along the direction perpendicular to the stretching direction with increasing strain. A weak scattering streak appears on the meridian of the SAXS pattern at the late stretching stage, which can be ascribed to the formation of microfibrils. ${ }^{32}$ Before stretching, the PLA sample at $120{ }^{\circ} \mathrm{C}$ shows four scattering rings related to the (010), (200/110), (203) and (210) planes from inner to outer in the WAXS pattern, revealing the formation of a more 

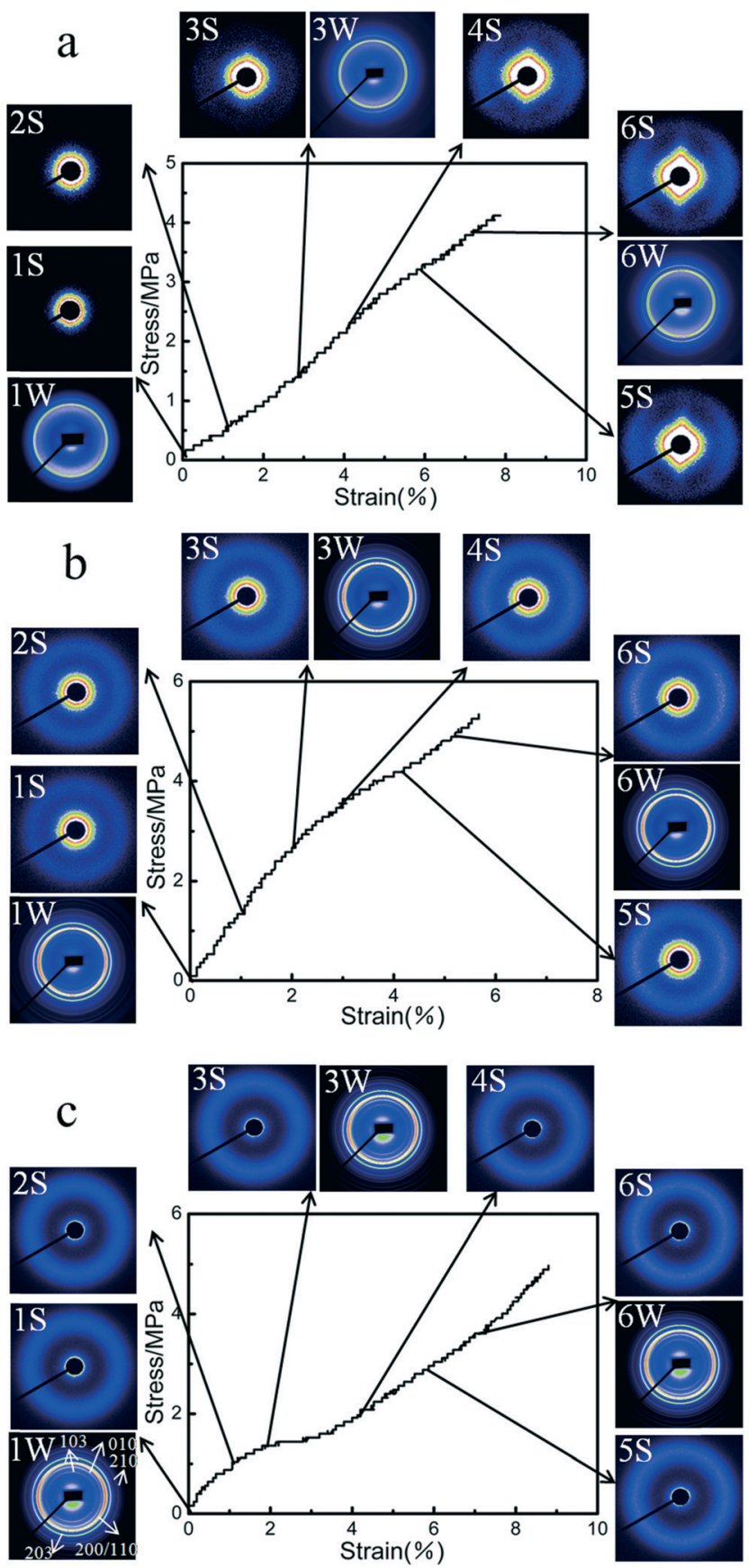

Fig. 2 Engineering stress-strain curves and selected 2D SAXS (1S-6S) and WAXS (1W, 3W and 6W) patterns collected at the corresponding strains during PLA stretching at different temperatures (a: $100{ }^{\circ} \mathrm{C}$, b: $120{ }^{\circ} \mathrm{C}$ and $\mathrm{C}: 150{ }^{\circ} \mathrm{C}$ ). The inserted numbers in the WAXS pattern of $1 \mathrm{~W}$ in Fig. $2 \mathrm{c}$ are the corresponding crystal planes of each scattering ring. The stretching direction is horizontal and is defined as the equator hereafter.

ordered crystalline structure than that at $100{ }^{\circ} \mathrm{C}$, as shown in Fig. 2 b. An isotropic scattering halo in the SAXS pattern is evidence of the existence of isotropic lamellae in the undrawn sample, indicating the high thermally-induced crystallinity of PLA before drawing at $120{ }^{\circ} \mathrm{C}$. With the stretching proceeding, no obvious changes in the WAXS patterns can be ob-

served. The isotropic scattering halo in the SAXS patterns orients gradually and presents two intense arcs on the equator, indicating the strain-induced orientation of the lamellar layer along the direction vertical to the stretching axis. As the drawing temperature increases up to $150{ }^{\circ} \mathrm{C}$, the undrawn PLA shows a highly ordered structure with high crystallinity, as indicated by more scattering rings in the WAXS pattern of $1 \mathrm{~W}$ and the broad scattering halo in the SAXS pattern of $1 \mathrm{~S}$ in Fig. 2c. Due to the much higher chain segment mobility of PLA at $150{ }^{\circ} \mathrm{C}$, no obvious changes can be observed from both the WAXS and SAXS patterns with increasing strain, except for a slight intensity enhancement of the SAXS pattern at the final stage of stretching related to the formation of a more ordered crystal.

Further treatments of WAXS and SAXS data are necessary to obtain more detailed information on the structural variations. The 1D WAXS profiles of PLA stretched within 100-150 ${ }^{\circ} \mathrm{C}$ were obtained by meridional integration and are shown in Fig. 3a-c. The WAXS profiles of undrawn PLA are similar to those of annealed PLA within $100-150{ }^{\circ} \mathrm{C}$ in terms of the diffraction peaks. The reported studies ${ }^{3,9,10,12}$ showed that only the $\alpha^{\prime}$ crystal of PLA can be obtained upon crystallization below $100{ }^{\circ} \mathrm{C}$, the coexistence of $\alpha^{\prime}$ and $\alpha$ forms can be observed between $100^{\circ} \mathrm{C}$ and $120^{\circ} \mathrm{C}$, and only the $\alpha$ form exists at or above $120^{\circ} \mathrm{C}$. The (010) and (203) planes are common to $\alpha$ and $\alpha^{\prime}$ forms, whereas the (103) and (210) reflections are related to the $\alpha$ form only. ${ }^{9,20}$ Therefore, the PLA sample before stretching at $100{ }^{\circ} \mathrm{C}$ contains both $\alpha$ and $\alpha^{\prime}$ forms, and those at $120{ }^{\circ} \mathrm{C}$ and $150{ }^{\circ} \mathrm{C}$ contain the $\alpha$ form only. Upon stretching within $100-150{ }^{\circ} \mathrm{C}$, the positions of all diffraction peaks of PLA shift to higher $2 \theta$ values, indicating the straininduced higher ordering of both $\alpha$ and $\alpha^{\prime}$ forms. The zoomed-up profiles of the (203) reflection of PLA drawn at $100{ }^{\circ} \mathrm{C}$ along with those of PLA annealed at $90{ }^{\circ} \mathrm{C}$ and $120{ }^{\circ} \mathrm{C}$ are shown in Fig. 3d. It is shown that the intensity of the diffraction peak of the (203) plane of PLA stretched at $100^{\circ} \mathrm{C}$ increases with strain and the position shifts to that of PLA annealed at $120^{\circ} \mathrm{C}$ related to the $\alpha$ form only, which implies that the structural ordering of the PLA crystal increases gradually ${ }^{9}$ and more $\alpha$ phases are formed from the stretched $\alpha^{\prime}$ phase and/or from the amorphous phase directly although the $\alpha^{\prime}$ phase still exists. However, it is difficult to identify the variations of the content ratio between the $\alpha^{\prime}$ and $\alpha$ phases induced by strain from the WAXS data quantitatively due to the significant similarity between the $\alpha$ and $\alpha^{\prime}$ forms except for the chain conformation and chain packing mode. ${ }^{33}$

The lattice spacing of the crystal planes can be calculated according to Bragg's equation with its peak position ${ }^{3}$ and be used to characterize the degree of chain packing of the crystal. ${ }^{9}$ The lattice spacings of the (200/110) and (203) planes, $d_{(200 / 110)}$ and $d_{(203)}$, of PLA during stretching within 100-150 ${ }^{\circ} \mathrm{C}$ were obtained and plotted with strain as a phase diagram regarding the $\alpha$ and $\alpha^{\prime}$ forms under stretching conditions, as shown in Fig. 4. The corresponding $d$ values of PLA annealed at $90{ }^{\circ} \mathrm{C}$ are also included for comparison. It can be seen that the $d_{(200 / 110)}$ and $d_{(203)}$ of PLA annealed at $90{ }^{\circ} \mathrm{C}$ related to the 

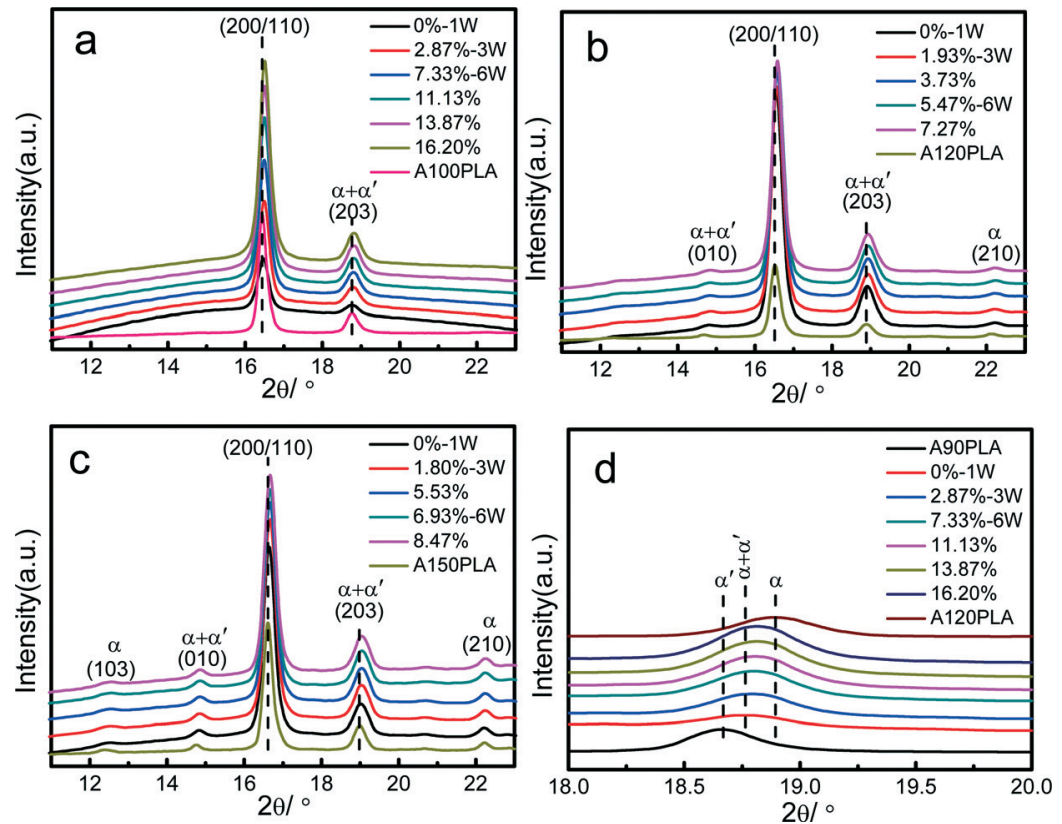

Fig. 3 1D WAXS profiles integrated along the meridian at the related strains of amorphous PLA stretched at (a) $100{ }^{\circ} \mathrm{C}$, (b) $120{ }^{\circ} \mathrm{C}$ and (c) $150{ }^{\circ} \mathrm{C}$, and (d) the variation of the (203) plane at related strains of PLA stretched at $100{ }^{\circ} \mathrm{C}$. The WAXS profiles corresponding to the WAXS patterns in Fig. 2 have been marked as "iW". For comparison, the WAXS profiles of PLA annealed at $90{ }^{\circ} \mathrm{C}, 100^{\circ} \mathrm{C}, 120^{\circ} \mathrm{C}$ and $150{ }^{\circ} \mathrm{C}$ for 12 hours are also included here. A90PLA, A100PLA, A120PLA and A150PLA correspond to the PLA samples annealed at $90{ }^{\circ} \mathrm{C}, 100{ }^{\circ} \mathrm{C}, 120{ }^{\circ} \mathrm{C}$ and $150{ }^{\circ} \mathrm{C}$ for 12 hours. For clarification, a vertical shift has been done for all WAXS profiles.
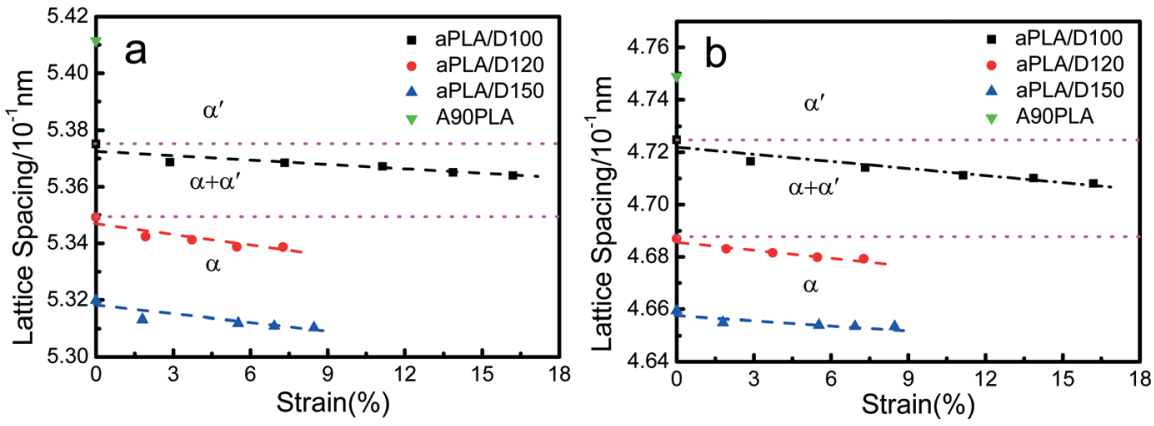

Fig. 4 The variations with strain of the lattice spacing of (a) (200/110) and (b) (203) planes of PLA stretched at $100{ }^{\circ} \mathrm{C}, 120{ }^{\circ} \mathrm{C}$ and $150{ }^{\circ} \mathrm{C}$. For comparison, the values for PLA annealed at $90^{\circ} \mathrm{C}$ for 12 hours are also included here. aPLA/D100, aPLA/D120 and aPLA/D150 correspond to amorphous PLA drawn at $100^{\circ} \mathrm{C}, 120^{\circ} \mathrm{C}$ and $150{ }^{\circ} \mathrm{C}$, and A90PLA relates to the PLA sample annealed at $90{ }^{\circ} \mathrm{C}$ for 12 hours.

$\alpha^{\prime}$ form only are much larger than those of PLA drawn within $100-150{ }^{\circ} \mathrm{C}$, revealing the much looser chain packing of the $\alpha^{\prime}$ form. With the strain increasing, the $d$ values of PLA drawn within $100-150{ }^{\circ} \mathrm{C}$ decrease linearly, which is obvious evidence of the strain-induced increase in structural ordering of both the $\alpha$ and $\alpha^{\prime}$ forms. Particularly upon stretching at $100{ }^{\circ} \mathrm{C}$, the $d$ values of the mixture of $\alpha$ and $\alpha^{\prime}$ forms drop closer to those at $120{ }^{\circ} \mathrm{C}$ related to the $\alpha$ form only, which means that the ordering degree of the $\alpha^{\prime}$ form of PLA increases gradually and it may partly transform into the more ordered $\alpha$ form upon stretching at $100{ }^{\circ} \mathrm{C}$. Besides stretching, the $\alpha^{\prime}$ form of PLA can also be transformed into the $\alpha$ form by heating up to around $160{ }^{\circ} \mathrm{C}$ just before its melting point, as reported by Zhang et al. ${ }^{9,14}$ and Kawai et al. ${ }^{10}$ They re- vealed that the transition of the $\alpha^{\prime}$ form into the $\alpha$ form during heating is a solid-solid phase transition.

The crystallinity of PLA during stretching within 100-150 ${ }^{\circ} \mathrm{C}$ was obtained by peak-fitting of the obtained WAXS profiles using the Jade 6.0 software with the fitting method proposed by Stoclet et al., ${ }^{1,19}$ which assumes Gaussian profiles for all scattering peaks and amorphous halos. The crystallinity was calculated using the area ratio of the crystal diffraction peaks and the total scattering peaks. The calculated crystallinity during stretching varying with drawing time is shown in Fig. 5. For comparison, the crystallinity of PLA annealed within $100-150{ }^{\circ} \mathrm{C}$ for 12 hours is also calculated and included here. As shown in Fig. 5, the initial crystallinity of PLA drawn at $120{ }^{\circ} \mathrm{C}$ is the highest among those drawn 


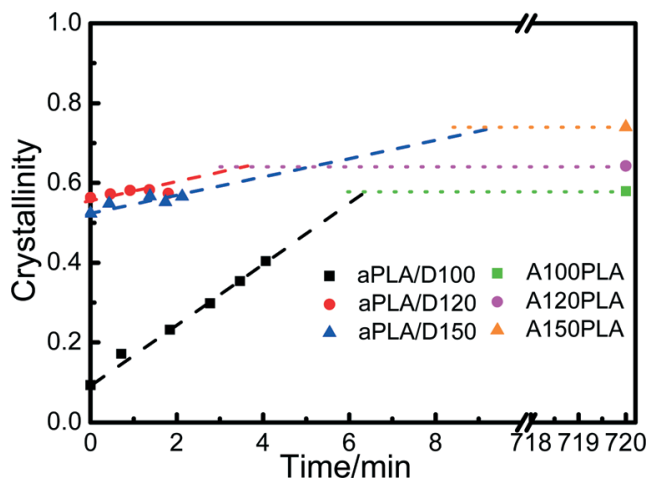

Fig. 5 The variation of crystallinity of PLA stretched within $100-150{ }^{\circ} \mathrm{C}$ with time (drawing time or annealing time). For comparison, the values for PLA annealed at $100{ }^{\circ} \mathrm{C}, 120{ }^{\circ} \mathrm{C}$ and $150{ }^{\circ} \mathrm{C}$ for 12 hours are also included here (aPLA/D100, aPLA/D120 and aPLA/D150 correspond to amorphous PLA drawn at $100{ }^{\circ} \mathrm{C}, 120{ }^{\circ} \mathrm{C}$ and $150{ }^{\circ} \mathrm{C}$. A100PLA, A120PLA and A150PLA correspond to the PLA samples annealed at 100 ${ }^{\circ} \mathrm{C}, 120^{\circ} \mathrm{C}$ and $150{ }^{\circ} \mathrm{C}$ for 12 hours).

within the measured temperatures, which is due to the highest quiescent crystallization rate of PLA at around 120 ${ }^{\circ} \mathrm{C} .{ }^{34}$ Upon stretching within $100-150{ }^{\circ} \mathrm{C}$, the crystallinity of the drawn PLA samples linearly increased with drawing time, especially that drawn at $100{ }^{\circ} \mathrm{C}$, which has the largest increment due to it being subjected to stretching. It is worth noting that the crystallinity of PLA drawn within $100-150{ }^{\circ} \mathrm{C}$ would increase linearly up to the values for PLA annealed at the same temperatures with much less drawing time (about a maximum of 9 minutes) compared to annealing time (720 minutes) if the sample was not broken during stretching, which reveals that the rate of strain-induced cold crystallization of PLA is much higher than that of quiescent cold crystallization within $100-150{ }^{\circ} \mathrm{C}$. This can be attributed to the coordination effects of strain-induced chain orientation and the high chain segment mobility on cold crystallization of PLA when stretched at high temperatures.

Based on the difference in thermally-induced initial crystallinity of amorphous PLA before stretching within 100-150 ${ }^{\circ} \mathrm{C}$, the above anomalous variation of Young's modulus of amorphous PLA with drawing temperature could be interpreted. The Young's modulus of a polymer can be influenced by the combined effects of initial crystallinity and temperaturerelated chain segment mobility. The higher initial crystallinity and the lower chain segment mobility correspond to higher Young's modulus. The chain segment mobility of PLA at $100{ }^{\circ} \mathrm{C}$ is the lowest but with the lowest crystallization rate. The crystallization of PLA at $120{ }^{\circ} \mathrm{C}$ is the fastest ${ }^{34}$ but with moderate chain segment mobility. The crystallization of PLA at $150{ }^{\circ} \mathrm{C}$ is also fast but with the highest chain segment mobility. Therefore, the Young's modulus of PLA drawn at 120 ${ }^{\circ} \mathrm{C}$ is the highest among those drawn at $100{ }^{\circ} \mathrm{C}, 120{ }^{\circ} \mathrm{C}$ and $150{ }^{\circ} \mathrm{C}$ as a result of the coordination effects of high initial crystallinity and moderate chain segment mobility. This implies that the Young's modulus of PLA is more dependent on the initial crystallinity at the lower drawing temperature and on the chain segment mobility at the higher drawing temper- ature, which supports the variation of the discrepancy of Young's modulus between annealed and amorphous PLA $(\Delta E)$ within a wider drawing temperature range $\left(70-150{ }^{\circ} \mathrm{C}\right)$, as shown in Fig. 1c. At lower drawing temperatures, i.e. 70$80^{\circ} \mathrm{C}, \Delta E$ is high and remains almost unchanged with drawing temperature, which is due to the fact that Young's modulus is mainly influenced by the initial crystallinity of the PLA samples and the difference in initial crystallinity between the annealed and amorphous PLA samples is large and constant within $70-80{ }^{\circ} \mathrm{C}$. At moderate drawing temperatures, i.e. 80$100{ }^{\circ} \mathrm{C}$, the effect of chain segment mobility on Young's modulus becomes stronger due to the increased drawing temperatures and can partly counteract the effect of the difference in initial crystallinity between the annealed and amorphous PLA samples, which leads to the onset of decrease in $\Delta E$. When the drawing temperature is higher than $100{ }^{\circ} \mathrm{C}$, the effect of high chain segment mobility induced by the high temperature on Young's modulus overcomes the effect of the difference in initial crystallinity between the annealed and amorphous PLA samples and trends to be dominated, making $\Delta E$ much smaller and even zero.

The meso-scale structure (the long period of stacked lamellar structure, the thickness of lamellar layer and amorphous layer in one long period) evolutions of PLA stretched within $100-150{ }^{\circ} \mathrm{C}$ can be analyzed according to the obtained SAXS data. The 1D SAXS profiles were obtained by integration taken along the equatorial direction and the meridional direction from the 2D SAXS patterns. The obtained SAXS profiles were Lorentz-corrected by multiplying $I(q)$ by $q^{2}$ and are shown in Fig. 6. Upon stretching at $100{ }^{\circ} \mathrm{C}$, both the scattering peak of the equatorial direction and that of the meridional direction appear gradually and become stronger with increasing strain, which indicates that the lamellar crystal forms and increases gradually with increasing strain. Meanwhile, the position of the scattering peaks of the two directions shifts to a higher $q$ value, revealing that the long periods of the stacked lamellar structure parallel and perpendicular to the stretching direction all decrease, which can be attributed to the significant increase of lamellar crystals. When drawn at $120{ }^{\circ} \mathrm{C}$, the scattering peak of the equatorial direction moves to a lower $q$ value, whereas that of the meridional direction shifts to a higher $q$ value, which indicates that the long period along the stretching direction becomes larger and that vertical to the stretching direction becomes smaller. However, upon stretching at $150{ }^{\circ} \mathrm{C}$, the position of the scattering peaks of the equatorial and meridional directions exhibits almost no change, revealing that the long periods parallel and perpendicular to the stretching direction remain almost unchanged.

To detect the different variations of the stacked lamellar structure of PLA drawn at different temperatures in detail, the long period of stacked lamellae, $L$, the thickness of the lamellar crystal, $L_{\mathrm{c}}$, and the orientation degree of the lamellar crystal, $f$, were obtained and analyzed. $L$ and $L_{\mathrm{c}}$ were calculated from the Lorentz-corrected SAXS profiles by using the one-dimensional electron density correlation function $K(z):^{35}$ 

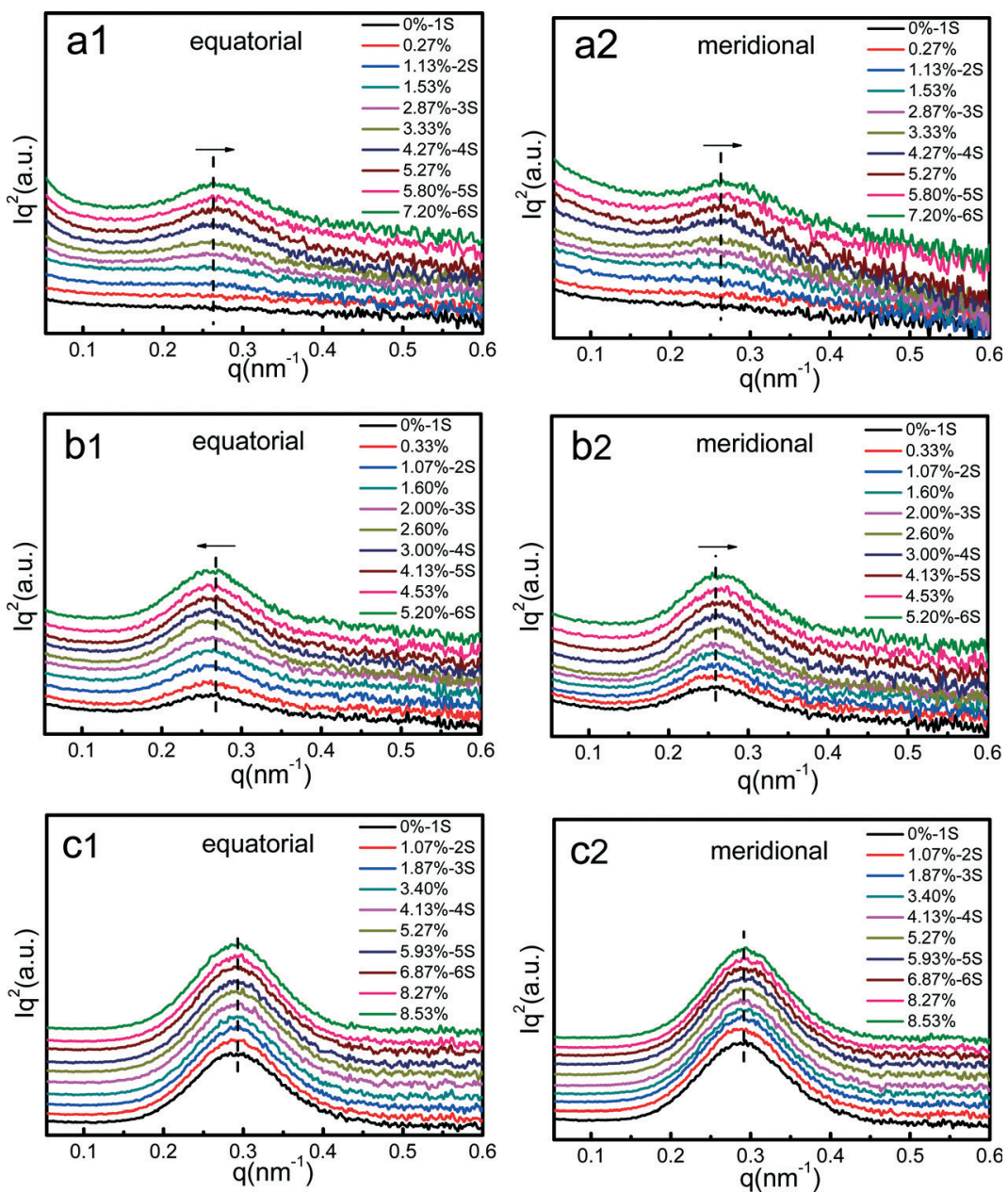

Fig. 6 1D SAXS profiles integrated along the equatorial and meridional directions at the related strains of amorphous PLA stretched at (a) $100{ }^{\circ} \mathrm{C}$, (b) $120{ }^{\circ} \mathrm{C}$ and (c) $150{ }^{\circ} \mathrm{C}$. The 1D SAXS profiles corresponding to the 2D WAXS patterns in Fig. 2 have been marked as "iS". For clarification, a vertical shift has been done for the SAXS profiles.

$$
K(z)=\frac{2}{\pi} \int_{0}^{\infty} q^{2} I(q) \cos (q z) \mathrm{d} q
$$

where $z$ is parallel to the drawing direction and $I(q)$ is the $1 \mathrm{D}$ intensity profile. Multiplication of $q^{2}$ and $I(q)$ is always carried out to account for the partially oriented structure. ${ }^{31}$ The orientation degree of the lamellar crystal, $f$, of PLA drawn within $100-150{ }^{\circ} \mathrm{C}$ was calculated based on the $360^{\circ}$ azimuthintegrated SAXS profiles, $I(\Phi)$, according to Herman's orientation function: ${ }^{5}$

$$
f=\frac{3\left(\cos ^{2} \phi\right)-1}{2}
$$

where $\Phi$ is the angle between the chain axis and the reference axis (stretching direction), and $\cos ^{2} \Phi$ is defined as:

$$
\cos ^{2} \phi=\frac{\int_{0}^{\frac{\pi}{2}} I(\phi) \cos ^{2}(\phi) \sin (\phi) \mathrm{d} \phi}{\int_{0}^{\frac{\pi}{2}} I(\phi) \sin (\phi) \mathrm{d} \phi}
$$

where $I(\Phi)$ is the scattering intensity along the angle $\Phi$.
The obtained $L, L_{\mathrm{c}}$ and $f$ of PLA drawn within $100-150{ }^{\circ} \mathrm{C}$ are shown in Fig. 7. Upon stretching at $100{ }^{\circ} \mathrm{C}$, no stacked lamellar structure appeared in the PLA sample with strain smaller than $1.5 \%$, due to the low crystallinity at this stage. Within the strain ranging from $1.5 \%$ to $5 \%$, the $L$ along the equator (along the stretching direction) and along the meridian (perpendicular to the stretching direction) begin to appear and are all decreased, meanwhile the $L_{\mathrm{c}}$ along the two directions are also decreased but with much smaller decrement. This means that the decrease in $L$ is mainly attributed to the decrease in thickness of the amorphous layer between the two lamellae in which the new lamellae are formed gradually, as revealed by the significant increase in crystallinity. On the other hand, the decrement of $L$ along the equator is slightly larger than that along the meridian, which can be because more lamellae are stretched and become oriented gradually along the direction perpendicular to the stretching axis, as shown in Fig. 7 d. Both the $L$ along the equator and that along the meridian remain almost unchanged after the strain becomes larger than $5 \%$. The constant $L$ along the equator may be attributed to the fact that the newly appeared 

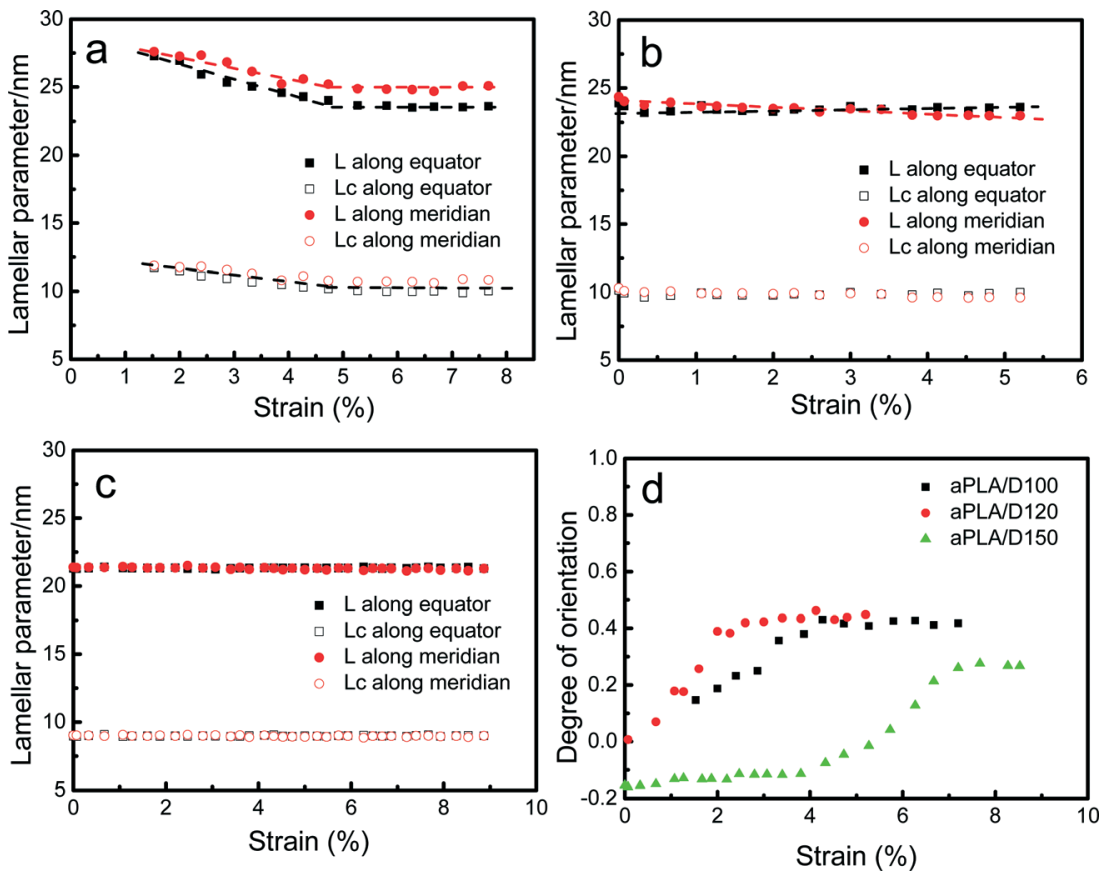

Fig. 7 The variations with strain of the long period, $L$, and the thickness of lamellae, $L_{c}$, of amorphous PLA stretched at (a) $100{ }^{\circ} \mathrm{C}$, (b) $120{ }^{\circ} \mathrm{C}$ and (c) $150{ }^{\circ} \mathrm{C}$, and (d) the variations with strain of the orientation degree of the lamellar crystal, $f$, of amorphous PLA stretched at $100{ }^{\circ} \mathrm{C}, 120{ }^{\circ} \mathrm{C}$ and $150{ }^{\circ} \mathrm{C}$ (aPLA/D100, aPLA/D120 and aPLA/D150, as shown in (d), correspond to amorphous PLA drawn at $100^{\circ} \mathrm{C}, 120^{\circ} \mathrm{C}$ and $150{ }^{\circ} \mathrm{C}$ ).

lamella-induced decrease of $L$ along the equator is almost counteracted by the strain-induced increase of amorphous layer thickness, and the constant $L$ along the meridian is due to the fact that the strain-induced decrease of amorphous layer thickness along the meridian is nearly offset by the increase of amorphous layer thickness due to the straininduced breaking, rotation and orientation of pre-existing lamellae between amorphous layers. Drawn at $120{ }^{\circ} \mathrm{C}$, the stacked lamellar structure exists initially in the PLA sample due to the high initial crystallinity. With increasing strain, the $L$ along the equator exhibits a slight increase and that along the meridian decreases slightly, whereas the $L_{\mathrm{c}}$ along the equator and meridian remain almost unchanged. Therefore, the increase of $L$ along the equator is expected to mainly originate from the strain-induced increase of amorphous layer thickness along the equator, and the decrease of $L$ along the meridian is mainly due to the strain-induced decrease of amorphous layer thickness along the meridian. Meanwhile, some lamellar crystals along the stretching direction are stretched to break, rotate and obtain a quick and high orientation along the direction vertical to the stretching axis, as shown in Fig. 7d, which weakens the effect of strain-induced variations of amorphous layer thickness on $L$ along the two directions and therefore leads to only a slight variation of $L$. Upon stretching at $150{ }^{\circ} \mathrm{C}$, the $L_{\mathrm{c}}$ along the two directions exhibit almost no change. Meanwhile, due to the very high chain relaxation at this temperature, the strain can induce very little variation in amorphous layer thickness along the two directions and a very slow and low orientation of lamellar crystals, which leads to the $L$ along the two directions almost unchanged during stretching, as shown in Fig. 7c.
It is worth noting that the thickness of the lamellar crystal of PLA stretched within $100-150{ }^{\circ} \mathrm{C}$ exhibits different variations with strain, i.e., having an obvious decrease first and then leveling off at $100{ }^{\circ} \mathrm{C}$, however, remaining almost unchanged with strain at 120 and $150{ }^{\circ} \mathrm{C}$, which can be attributed to the partial transition of the $\alpha^{\prime}$ form to the $\alpha$ form induced by strain. The reported results revealed that the $\alpha^{\prime}$ form of PLA contains a disordered multi-domain structure in which the domains containing the loose chain packing and disordered $10_{3}$ helical conformations are gathered together with a mismatched relative height between the neighboring domains. $^{12,15}$ Based on the reported results and the WAXS/ SAXS results in the present work, a schematic structural model as shown in Fig. 8 was established to better understand the structural variations of PLA stretched within 100$150{ }^{\circ} \mathrm{C}$. Upon stretching at $100{ }^{\circ} \mathrm{C}$, the initially formed lamellar crystal consists of the $\alpha^{\prime}$ form with a mismatched relative height between the neighboring domains. With increasing strain, the $\alpha^{\prime}$ form is stretched and transformed partially into the more ordered $\alpha$ form, as revealed by the results in Fig. 4 and 5, via the relative height matching of the neighboring domains along with the ordering of chain conformation and the regularization of chain packing. ${ }^{15}$ Therefore, the not well-ordered crystalline domains in the lamellar crystal are stacked more closely and the lamellar thickness decreases obviously. Due to the limited transition of the $\alpha^{\prime}$ form to the $\alpha$ form in PLA sample stretched at $100{ }^{\circ} \mathrm{C}$, the lamellar thickness exhibits little change at the late stage of stretching. Upon stretching at 120 and $150{ }^{\circ} \mathrm{C}$, no transition of the $\alpha^{\prime}$ form to the $\alpha$ form occurred. The strain can only induce the increase in the degree of chain packing of the $\alpha$ form, which 


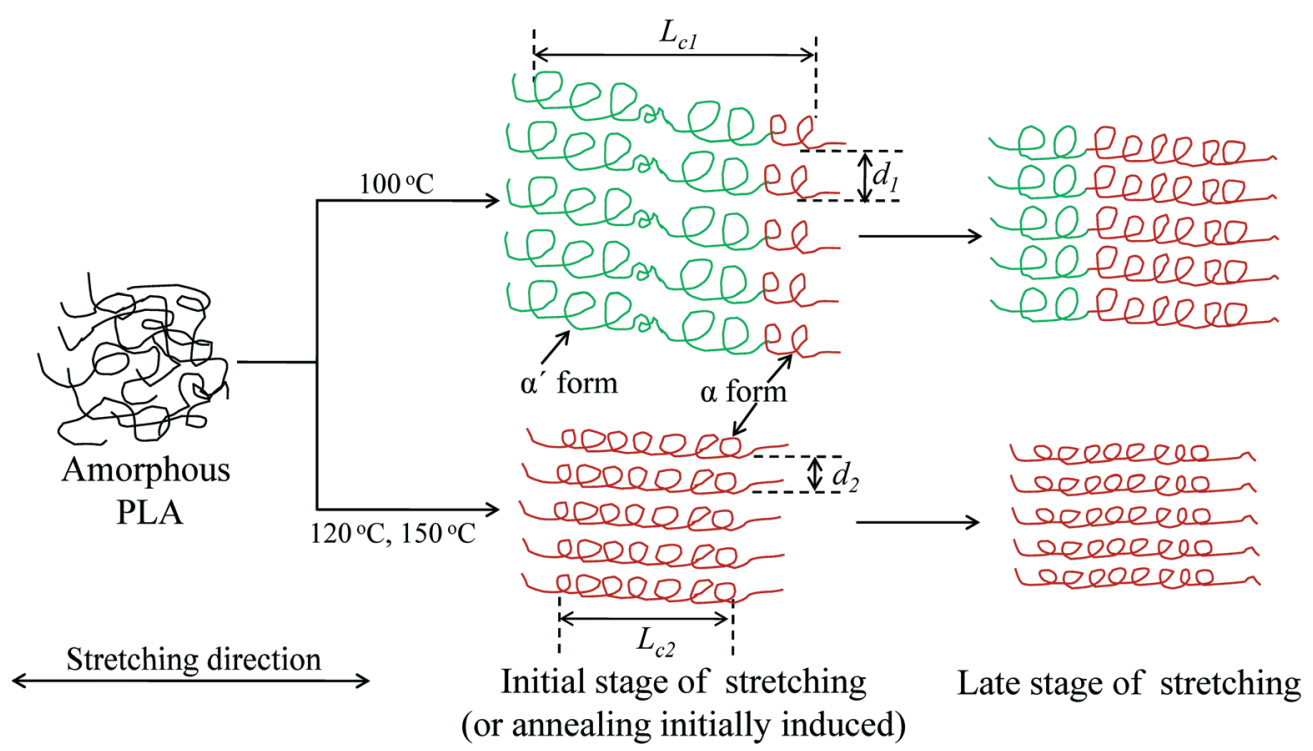

Fig. 8 The schematic structural model of amorphous PLA stretched within 100-150 ${ }^{\circ} \mathrm{C}$. " $d$ " corresponds to the lattice spacing of crystal planes, and " $L_{c}$ " corresponds to the lamellar thickness. After stretching at $100{ }^{\circ} \mathrm{C}, d_{1}$ and $L_{\mathrm{c} 1}$ are all decreased which is induced by the partial transition of the $\alpha^{\prime}$ form to the $\alpha$ form. However, upon stretching at $120{ }^{\circ} \mathrm{C}$ and $150{ }^{\circ} \mathrm{C}$, only $d_{2}$ exhibits a slight decrease and $L_{\mathrm{c} 2}$ remains almost unchanged as no transition of the $\alpha^{\prime}$ form to the $\alpha$ form occurs.

has little effect on the stacked lamellar structure. Therefore, the lamellar thickness remains almost unchanged with strain.

\section{Conclusions}

The deformation behaviors and structure evolutions of amorphous PLA samples stretched within $100-150{ }^{\circ} \mathrm{C}$ were investigated with uniaxially tensile deformation combined with in situ synchrotron WAXS and SAXS measurements. The excellent mechanical properties of PLA stretched at $120{ }^{\circ} \mathrm{C}$ are attributed to the cooperative effects of high thermally-induced initial crystallinity and moderate chain segment mobility. The stretching can induce the increase in structural ordering of both $\alpha^{\prime}$ and $\alpha$ forms of PLA drawn within $100-150{ }^{\circ} \mathrm{C}$ with the shift of diffraction peaks to higher $2 \theta$ values and the linear decrease in lattice spacing of the (200/110) and (203) planes. Especially for drawing at $100{ }^{\circ} \mathrm{C}$, the initial peak of the (203) plane related to the coexistence of $\alpha^{\prime}$ and $\alpha$ forms shifts gradually closer to that of PLA annealed at $120{ }^{\circ} \mathrm{C}$ related to the $\alpha$ form only, which implies that the structural ordering of the PLA crystal enhances gradually and more $\alpha$ phases can be formed from the stretched $\alpha^{\prime}$ phase and/or from the amorphous phase directly although the $\alpha^{\prime}$ phase still exists. The crystallinity of PLA stretched within 100-150 ${ }^{\circ} \mathrm{C}$ increases linearly with drawing time, and the rate of strain-induced cold crystallization is much higher than that of quiescent cold crystallization within $100-150{ }^{\circ} \mathrm{C}$.

The long period of PLA stretched within $100-150{ }^{\circ} \mathrm{C}$ exhibits different variations. Drawn at $100{ }^{\circ} \mathrm{C}$, with strain less than $5 \%$, the $L$ along and vertical to the stretching direction are all decreased obviously, which is mainly attributed to the decrease in thickness of the amorphous layer in which new lamellae are formed gradually. Due to more lamellae being oriented vertical to the stretching axis, the decrement of $L$ along the stretching direction is slightly larger than that vertical to the stretching axis. With strain larger than $5 \%$, the $L$ along the two directions remain almost unchanged, due to the balance between the variations of amorphous layer thickness induced by strain and by lamellae. At $120{ }^{\circ} \mathrm{C}$, the $L$ along and vertical to the stretching direction have opposite changes but all with very small amplitudes, which can be due to the combined effects of the strain and lamellar orientation on amorphous layer thickness. Upon stretching at $150{ }^{\circ} \mathrm{C}$, the $L$ along the two directions remain almost unchanged, due to the strain-induced small variation of amorphous layer thickness and a very slow and low orientation of existing lamellae.

Furthermore, the lamellar thickness also exhibits different variations with strain within $100-150{ }^{\circ} \mathrm{C}$, which can be attributed to the partial transition of the $\alpha^{\prime}$ form of PLA to its $\alpha$ form induced by strain.

\section{Acknowledgements}

This work was supported by the National Natural Science Foundation of China (51173130, 21274149, 21374077, 51473166 and 51573131).

\section{References}

1 G. Stoclet, R. Seguela, J. M. Lefebvre, S. Elkoun and C. Vanmansart, Macromolecules, 2010, 43, 1488-1498.

2 G. Stoclet, S. Elkoun, V. Miri, R. Seguelal and J. M. Lefebvre, Int. Polym. Process., 2007, 22, 385-388.

3 S. Y. Huang, H. F. Li, S. C. Jiang, X. S. Chen and L. J. An, Polymer, 2011, 52, 3478-3487. 
4 X. Q. Zhang, K. Schneider, G. M. Liu, J. H. Chen, K. Brüning, D. J. Wang and M. Stamm, Polymer, 2011, 52, 4141-4149.

5 P. T. Xiao, H. F. Li, S. Y. Huang, H. Y. Wen, D. H. Yu, Y. R. Shang, J. Q. Li, Z. H. Wu, L. J. An and S. C. Jiang, CrystEngComm, 2013, 15, 7914-7925.

6 S. Saeidloua, M. A. Huneaulta, H. B. Li and C. B. Park, Prog. Polym. Sci., 2012, 37, 1657-1677.

7 G. M. Liu, X. Q. Zhang and D. J. Wang, Adv. Mater., 2014, 26, 6905-6911.

8 P. De Santis and A. J. Kovacs, Biopolymers, 1968, 6, 299-306.

9 J. M. Zhang, K. Tashiro, H. Tsuji and A. J. Domb, Macromolecules, 2008, 41, 1352-1357.

10 T. Kawai, N. Rahman, G. Matsuba, K. Nishida, T. Kanaya, M. Nakano, H. Okamoto, J. Kawada, A. Usuki, N. Honma, K. Nakajima and M. Matsuda, Macromolecules, 2007, 40, 9463-9469.

11 W. Hoogsteen, A. R. Postema, A. J. Pennings and G. ten Brinke, Macromolecules, 1990, 23, 634-642.

12 J. M. Zhang, Y. X. Duan, H. Sato, H. Tsuji, I. Noda, S. K. Yan and Y. Ozaki, Macromolecules, 2005, 38, 8012-8021.

13 C. Y. Chen, C. F. Yang, U. S. Jeng and A. C. Su, Macromolecules, 2014, 47, 5144-5151.

14 J. M. Zhang, C. W. Li, Y. X. Duan, A. J. Domb and Y. Ozaki, Vib. Spectrosc., 2010, 53, 307-310.

15 K. Wasanasuk and K. Tashiro, Polymer, 2011, 52, 6097-6109.

16 M. Cocca, M. L. Di Lorenzo, M. Malinconico and V. Frezza, Eur. Polym. J., 2011, 47, 1073-1080.

17 K. Wasanasuk and K. Tashiro, Macromolecules, 2011, 44, 9650-9660.

18 C. B. Zhou, H. F. Li, Y. Zhang, F. F. Xue, S. Y. Huang, H. Y. Wen, J. Q. Li, J. C. Christiansen, D. H. Yu, Z. H. Wu and S. C. Jiang, CrystEngComm, 2015, 17, 5651-5663.

19 G. Stoclet, R. Seguela, J.-M. Lefebvre and C. Rochas, Macromolecules, 2010, 43, 7228-7237.
20 G. Stoclet, R. Seguela, C. Vanmansart, C. Rochas and J.-M. Lefebvre, Polymer, 2012, 53, 519-528.

21 J. C. Velazquez-Infante, J. Gamez-Perez, E. A. FrancoUrquiza, O. O. Santana, F. Carrasco and M. L. Maspoch, J. Appl. Polym. Sci., 2013, 127, 2661-2669.

22 R. H. Lv, B. Na, N. N. Tian, S. F. Zou, Z. J. Li and S. C. Jiang, Polymer, 2011, 52, 4979-4984.

23 J. Mulligan and M. Cakmak, Macromolecules, 2005, 38, 2333-2344.

24 J. Hu, T. P. Zhang, M. G. Gu, X. Chen and J. M. Zhang, Polymer, 2012, 53, 4922-4926.

25 R. H. Lv, S. F. Zou, B. Na, H. Y. Pan and H. Y. Deng, Polym. Eng. Sci., 2013, 53, 21-26.

26 R. H. Lv, S. F. Zou, B. Na, H. Y. Deng and Z. W. Yu, Polym. Eng. Sci., 2013, 53, 2568-2572.

27 A. Mahendrasingam, D. J. Blundell, M. Parton, A. K. Wright, J. Rasburn, T. Narayanan and W. Fuller, Polymer, 2005, 46, 6009-6015.

28 Z. H. Li, Z. H. Wu, G. Mo, X. Q. Xing and P. Liu, Instrum. Sci. Technol., 2014, 42, 128-141.

29 Z. H. Li, Chin. Phys. C, 2013, 37, 110-125.

30 Y. R. Shang, X. X. Zhang, H. Xu, J. Q. Li and S. C. Jiang, Polymer, 2015, 77, 254-265.

31 G. M. Liu, L. C. Zheng, X. Q. Zhang, C. C. Li, S. C. Jiang and D. J. Wang, Macromolecules, 2012, 45, 5487-5493.

32 H. L. Guo, Y. Zhang, F. F. Xue, Z. W. Cai, Y. R. Shang, J. Q. Li, Y. Chen, Z. H. Wu and S. C. Jiang, CrystEngComm, 2013, 15, 1597-1606.

33 D. Dikovsky, G. Marom, C. A. Avila-Orta, R. H. Somani and B. S. Hsiao, Polymer, 2005, 46, 3096-3104.

34 M. Yasuniwa, S. Tsubakihara, K. Iura, Y. Ono, Y. Dan and K. Takahashi, Polymer, 2006, 47, 7554-7563.

35 K. R. Reddy, K. Tashiro, T. Sakurai, N. Yamaguchi, S. Sasaki, H. Masunaga and M. Takata, Macromolecules, 2009, 42, 4191-4199. 